\title{
Detection of Antibiotic Residues in Sheep Liver at Almoilih Slaughter Houses at Karrey Locality, Khartoum State, Sudan
}

\author{
Mohamed Ismail Mohamed Fangama ${ }^{1 *}$, Ismail Mohamed Fangama ${ }^{2}$, \\ Siham Elias Suliman ${ }^{3}$ and Mohamed Abdel Salam Abdalla ${ }^{3}$ \\ ${ }^{1}$ Ministry of Health, Qatar Public Health Department, Sudan \\ ${ }^{2}$ College of Forestry and Range Science (SUST), Sudan \\ ${ }^{3}$ College of Veterinary Medicine (SUST), Sudan
}

*Corresponding author

\section{A B S T R A C T}

Keywords

Sheep liver,

Antibiotic residues,

Inhibition zone,

One plate test

Article Info

Accepted:

22 January 2018

Available Online:

10 February 2019
The objective of this study was to detect antibiotic residues in sheep liver collected from Albaraka and Alsabaloga slaughterhouses at Karray locality in Khartoum state. A total of 28 sheep liver samples were taken to microbiology laboratory, microbial inhibition one plate of Bacillus subtilis in agar medium was used. The results revealed that $7(25 \%)$ of sheep livers were positive to antibiotic, while 21 $(75 \%)$ of them were negative. In conclusion the use of antibiotics in food producing animals' must be under control; it should be given at recommended dose with appropriate supervision. Adequate holding period or withdrawal period should be observed in all slaughtered animals following therapeutic use of antibiotics in treating sick animals, in addition to continuous training veterinarians to know the importance of withdrawal period in avoiding tissue residues.

\section{Introduction}

In developed countries the uses of antibiotics in animal husbandry, whether as prophylactic or therapeutic agents or as growth promoters in feeding stuffs are needed to restrict the potential problems resulting from the misuse and extra-label (Report, 1969). Veterinary drugs residues usually accumulate in the liver or kidney rather than other tissues. It has been noted that different residue levels can be found in different tissue positions such as site and route of administration (Doyle, 2006).
Residues from these substances are present in edible tissues milk and eggs and may exert different levels of toxicity on consumers upon consumption (Suhren et al., 1996), with anemia, hypersensitivity and resistance to antibiotics. Screening of animal products for veterinary drugs began mainly with the dairy industry to overcome problems related to fermentative dairy production, from 1970s regulatory screening of slaughtered animals was started (Mariël, 2007) to prevent or minimized the harmfully effect of the residues. Microbiological techniques are the 
basis of screening methods for monitoring the presence of veterinary drug residues, which possess antibiotic or antibacterial activity in foods of animal origin (Bogaerts and Wolf, 1980). Screening methods have acceptable false-positive result rates (Heitzman, 1992; Korsrud and MacNeil, 1987) and allow detection of a wide spectrum of antibiotics (Aerts et al., 1995; Haasnoot et al., 1999). These methods use liquid or solid media inoculated with a standard culture of test microorganisms, e.g. Geoba cillus stearothermophilus var. calidolactis C 953, Bacillus subtilis, Bacillus cereus, Micrococcus luteus, Escherichia coli, Bacillus megatherium, or Streptococcus thermophilus (Botsoglou and Fletouris, 2001; Heeschen, 1993).

The detection methods based on microbial inhibition are able to detect a wide range of antimicrobials, very cheap, easy to apply but they are lack of specificity when compare with the chemical methods, such as HPLC and GC-MS are usually sensitive enough to comply with maximum residue limits (MRLs) but are too specific and expensive for routine screening purposes (Bogaerts and Wolf, 1980).

The four-plate test (4PLT) has been recognized in Europe as a valuable method for the detection of antibiotic residues. However it was designed for meat and the use of four different agar diffusion plates makes it rather expensive and time consuming. This paper describes a one-plate screening method (OPS) for antibiotic residues in slaughter animals that has been used in Belgium for EEC screening purposes.

The method is based on the microbiological detection of antibiotic residues by growth inhibition of Bacillus subtilis in agar medium (Wenzel, 1982). The aim of the paper was to detect and identify the antibacterial residues in sheep liver and to test bacterial growth inhibition.

\section{Materials and Methods}

\section{Study area}

The samples were collected from slaughter houses at Almoilih aera in Karrey Locality, Khartoum State in January 2019.

\section{Sample size}

Twenty eight sheep liver samples were selected randomly from slaughter houses according to Non-probability sampling methods (Thrusfield, 2007).

\section{Sample collection}

The 28fresh slaughtered sheep liver samples were transported to the laboratory of Microbiology at the College of Veterinary Medicine in Khartoum. Then15 grams were taken from each liver. The samples were put in plastic bag, labeling and stored in ice keeper.

\section{Preparation of samples}

Samples were removed from the deep-freeze and allowed to reach a temperature of about 5 'C, before the outer (contaminated) surface was removed with a sterile scalpel. A cylindrical piece of liver was removed from each sample using a sterile cork borer $(8 \mathrm{~mm}$ internal diameter), $2 \mathrm{~mm}$ thick, were cut from it. The B. subtilis plates were incubated at $30^{\circ} \mathrm{C}$ for $18-24 \mathrm{~h}$. A positive test result was recorded when inhibition zone not less than 1$2 \mathrm{~mm}$ across.

\section{Antibiotic detection}

The One plate Screening method (OPS) was used Bacillus Subtilis DSM618. 


\section{Preparation of test plates with $B$. subtilis CCM 4062}

The $\mathrm{pH} 6$ test agar was heated to $55{ }^{\circ} \mathrm{C}$ and inoculated with $B$. subtilis spore suspension to approximately $104 \mathrm{CFU} \mathrm{ml}^{-1}$. The agar with the test strain was pipetted at $4 \mathrm{ml}$ doses to pre-heated sterile glass Petri dishes of $90 \mathrm{~mm}$ in diameter.

\section{Culture medium}

Standard II nutrient agar (Merck 7883) was prepared with $0-4 \%(\mathrm{w} / \mathrm{v})$ dextrose. The medium was sterilized by autoclaving at $121^{\circ} \mathrm{C}$ for $20 \mathrm{~min}$. The $\mathrm{pH}$ was adjusted to 7 \pm 00.5 with IN $\mathrm{NaOH}$ and IN HC1. When the medium had cooled to $50^{\circ} \mathrm{C}$, trimethoprim at a concentration of $0-2 / \mathrm{ig} / \mathrm{ml}$ agar and a spore suspension (Merck 10649) containing 104 Bacillus subtilis BGA spores per $\mathrm{ml}$ were added. Fourteen $\mathrm{ml}$ of the culture medium was poured into $9 \mathrm{~cm}$ diameter petri dishes.

The solidified agar medium was then kept upside down in the refrigerator at $4{ }^{\circ} \mathrm{C}$ in plastic bags. The plates were used between 1 and 7 days after preparation (Koenen Dierick et al., 1995). An incision was made into the liver sample to have around 0.5 gram in $5 \mathrm{~mm}$ thick to place immediately into the Petri dish.

\section{Cultivation media and solutions}

In order to prepare test plates with B. subtilis, test agar pH 6 was used. Further, sporulation medium was used (containing, in $500 \mathrm{ml}$, proteose peptone $1.725 \mathrm{~g}$ (HiMedia), casein enzyme hydrolysate1.725 g (HiMedia), $\mathrm{NaCl}$ $2.55 \mathrm{~g}$; Agar No. 1.

6.5 g (Oxoid, 2006); potassium dihydrogen phosphate $0.5 \mathrm{~g}$ (KH2PO4, Merck, Darmstadt, Germany) pH 7, sterilized at 121 ${ }^{\circ} \mathrm{C}$ for $15 \mathrm{~min}$.

\section{The principle of method}

The principle of the test is preparing plates seeded with sensitive bacteria (Bacillus subtilis) at specific conditions that can presumptively indicate the presence of specific antimicrobial group residues. The samples can be applied on top of, the agar layer. After over-night incubation, the presence of an antimicrobial residue becomes visible as an inhibition zone around the sample. The size of the inhibition zone depends on the type of residue and its concentration, while the sensitivity of the test is affected by many factors, such as indicator organism, $\mathrm{pH}$, type of growth medium, and thickness of the agar layer (Bovee and Pikkemaat, 2009).

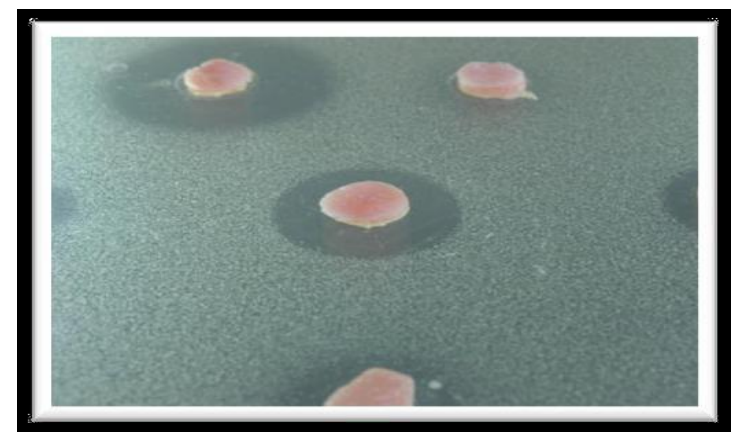

Figure.1 Muscle samples on a plate of FPT (Pikkemaat, 2009)

\section{Preparation of $\boldsymbol{B}$. subtilis spore suspension}

The B. subtilis spore suspension was prepared in accordance with the method of Bogaerts and Wolf (1980).

\section{Factors may influence sensitivity results of agar diffusion methods}

A number of factors may influence sensitivity results of agar diffusion methods besides the type of the test organism. It has been reported that the results might be affected by, e.g., the composition of the sample tested, agar 
thickness, concentration of the test strain spores in the medium, technique of sample application, agar $\mathrm{pH}$, evaluation of results, etc.( Pavlina et al., 2010)

\section{Data analysis}

The data was analyzed by using SPSS (Statistical Package for Social Science) version 24.

\section{Results and Discussion}

The results in Table 1 and Figure 1 about 25 $\%$ of the sheep liver samples were positive to antibiotics while $75 \%$ was negative. Relationship between the percentage of positive inhibition zone (IZ) higher than $2 \mathrm{~mm}$ or less than $2 \mathrm{~mm}$ and negative $\mathrm{IZ}<2 \mathrm{~mm}$ the analysis concentration was calculated, from which the calculations were made of the concentration threshold value at which the tests become unreliable and, at the same time, a concentration to which the given strain is sensitive. When evaluating results in individual Petri dishes, they measured the diameter of the inhibition zone (IZ) of all samples there, and then they determined the mean diameter of IZ in $\mathrm{mm}$. A sample was considered as positive when the mean diameter of IZ thus calculated was $\geq 2 \mathrm{~mm}$. The method's sensitivity to an antimicrobial substance was defined as the lowest concentration at which a positive result was obtained. However in the research, a method was considered as sufficiently sensitive at a given antibiotic concentration when a positive result, i.e. $\mathrm{IZ} \geq 2 \mathrm{~mm}$, was obtained with all the samples (Pavlina et al., 2010). This result is closed to the study conducted with (Hind et al., 2014), he found a total of 221poultry tissue samples screened for antibiotic residues were $27 \%$ of the samples tested positive residues and $73 \%$ were negative. Also this result similar to the study of (Shahid et al., 2007) done in Pakistan using B. subtilis as a test organism, screening of AMR in a total of 100 broiler tissue samples (33 livers, 33 kidney and 33 muscles) revealed that $13(39.4 \%)$ livers, 9(27.3\%) kidneys and $7(20.6 \%)$ muscles contained antimicrobial residues.

Table. 1 The distribution of antibiotics in the sheep liver

\begin{tabular}{|l|c|c|}
\hline \multicolumn{1}{|c|}{ Value } & Frequency & Percentage \\
\hline Positive & 7 & 25.0 \\
\hline Negative & 21 & 75.0 \\
\hline Total & 28 & 100.0 \\
\hline
\end{tabular}

The microbiological methods for screening the antibiotics it's still useful and coast less for monitoring the antibiotics in animal products especially for the large herds in developing countries to avoid the harmful residues to human and animal's health.

\section{References}

Aerts MML., Hogenboom A.C., Brinkman, UA. (1995). Analytical Strategies for the Screening of Veterinary Drugs and their
Residues in Edible Products. J. Chromatogr., 667: 1-20.

Bogaerts R., Wolf F. (1980). A standardised Method for the Detection of Residues of Antibacterial Substances in Fresh Meat. Fleischwirtschaft, 60, 672-673.

Botsoglou, N. A. - Fletouris, D. J. (2001). Drug Residues in Foods. 1st ed. New York: Marcel Dekker, 1194 pp.

Bovee, T.F. and M.G. Pikkemaat. (2009). Bioactivity-based Screening of Antibiotics and Hormones. Journal of Chromatography 
A, 1216(46): p. 8035-8050.

Doyle, M. E. (2006). Veterinary Drug Residues in Processed Meat-potential Health Risk. A review of the Scientific Literature.

Haasnoot, W., Stouten, P., Cazemier, G., Lommen, A., Nouws, F.M., Keukens, H.J. (1999). Immunochemical Detection of Aminoglycosides in Milk and Kidney. Analyst; 124: 301-5.

Heeschen, W. H. (1993). Residues of Antibiotics and Sulfonamides in Milk. In: Bulletin of the International Dairy Federation 283/1993: Inhibitory Substances in Milk current Analytical Practice. Brussels: International Dairy Federation, pp. 3-12.

Heitzman, RJ. (1992). Agriculture Veterinary Drug Residues: Residues in Food Producing Animals and their Products: Reference Materials and Methods. Luxembourg: Office for Official Publications of the European Communities, 17.

Hind, A. Elnasri, Adil, M. Salman and Samah A. El Rade. (2014). Screening of Antibiotic Residues in Poultry Liver, Kidney and Muscle in Khartoum State, Sudan. Journal of Applied and Industrial Sciences, 2 (3): 116-122.

Koenen-Dierick, K., L. Okerman; L. Dezutter; J. M. Degroodt, J. Van Hoof and S. Srebnik. (1995). A one-plate Microbiological Screening Test for Antibiotic Residue Testing in Kidney Tissue and Meat: An Alternative to the EEC Four-plate Method. Food Additives and Contaminants, Vol. 12, NO. 1, 77-82.

Korsrud, G, MacNeil JD (1987). A Comparison of Three Bioassay Techniques and High Performance Liquid Chromatography for the Detection of Chlortetracycline Residues in Swine Tissues. Food Addit Contam 5: 149-53.

Mariël, GP. (2007). Microbial Screening Methods for Detection of Antibiotic Residues in Slaughter Animals. Anal Bioanal Chem., 395(4): 893-905.

Oxoid, LTD. (2006). The oxoid Manual.Ninth edition. Oxoid, Wade Road, Basingstoke, Hampshire.

Pavlina, Navratilova ;Jana, Vyhnalkova; Jaroslava, Jerabkova; Bohumire, Janstova; Michaela,Drackova; Ivana, Borkovcova; Lenka, Vorlova. (2010). Utilization of $B$. cereus and $B$. subtilis Strains in Plate Diffusion Methods for the Detection of Tetracycline Residues in Milk. Journal of Food and Nutrition Research Vol. 49, No. 1, pp. 37-44.

Pikkemaat, M.G. (2009). Microbial Screening Methods for Detection of Antibiotic Residues in Slaughter Animals. Analytical and Bioanalytical Chemistry, 395(4): p. 893-905.

Report (1969). Joint Committee on the Use of Antibiotics in Animal Husbandry and Veterinary Medicine. Cmnd. 4190. London: HMSO.

Shahid, M.S., Muhammad, S., Hameed, S.H. (2007). Evaluation of a Microbiological Growth Inhibition Assay as a Screening Test for the Presence of Antibiotic Residues in Poultry Meat .American Journal of Food Technology; Vol. 2 5, p. 457-461.

Suhren, G., Reichmuth, J. and Walte, H. G. (1996). Detection of Beta-lactam Antibiotics in Milk by the Penzymtest. Milchwissenschaft (Germany).

Thrusfield, M. (2007) Veterinary Epidemiology. 3rd ed., Ch. 13. Black Well Science Ltd., United Kingdom. Pp. 228-246.

Wenzel, S. (1982), Verbesserung des Hemmstofftestes Durch Zusatz von Trimethoprim Zum Nachweis vonSulfonamiden. Aurchiv für Lebensmittelhygiene, 33, 109-136.

\section{How to cite this article:}

Mohamed Ismail Mohamed Fangama, Ismail Mohamed Fangama, Siham Elias Suliman and Mohamed Abdel Salam Abdalla. 2019. Detection of Antibiotic Residues in Sheep Liver at Almoilih Slaughter Houses at Karrey Locality, Khartoum State, Sudan. Int.J.Curr.Microbiol.App.Sci. 8(02): 3192-3196. doi: https://doi.org/10.20546/ijcmas.2019.802.372 